\title{
The Preliminary Literature Review of Proactive Behavior
}

\author{
Xi Li \\ School of Management, Jinan University, Guangzhou, China \\ Email: joylx07@163.com
}

How to cite this paper: $\mathrm{Li}, \mathrm{X}$. (2020). The Preliminary Literature Review of Proactive Behavior. American Journal of Industrial and Business Management, 10, 915-919. https://doi.org/10.4236/ajibm.2020.105061

Received: April 13, 2020

Accepted: May 5, 2020

Published: May 8, 2020

Copyright ( 2020 by author(s) and Scientific Research Publishing Inc. This work is licensed under the Creative Commons Attribution International License (CC BY 4.0).

http://creativecommons.org/licenses/by/4.0/

\begin{abstract}
In the era of knowledge economy, more and more organizations rely on employees' proactive behavior to promote creativity, innovation and change and gain the competitive advantage of the organization. As for the proactive behavior, a large number of scholars have studied proactive behavior with the conceptual connotation, antecedent variables and action mechanism in different situations. This paper summarizes the main points of previous studies, on this basis, puts forward the way to improve employees' proactive behavior and proposes some suggestions.
\end{abstract}

\section{Keywords}

Proactive Behavior, Concept, Suggested Measures

\section{Introduction}

With the emergence of super-competitive environment, the requirements of enterprises for employees are not limited to passive acceptance of orders and commands, but more employees need to give play to their own internal initiative consciousness and use their own initiative to create more value for the enterprise, such as proactive prediction of the organizational environment, proactive search for opportunities to solve problems, proactive promotion of organizational reform and innovation. The essence of proactive behavior is the individual behavior driven by positive work motivation. Existing research shows that proactive behavior has a significant positive effect on organizational performance improvement. Since it is the initiative behavior of employees, driven by their internal motivation, it can obtain better work outcomes, such as work performance, job satisfaction, role innovation (Ashforth et al., 2007). Based on the review of the literature, this paper summarizes the conceptual connotation and antecedent variables of proactive behaviors, and on this basis, proposes methods to improve 
proactive behaviors, and points out the deficiencies of existing researches and future research directions.

\section{Concept of Proactive Behavior}

According to the social cognition theory, human beings are not only the products of the environment, but also reflect, self-regulate and actively transform the environment. When an individual has a long-term goal, he/she will take into account what will happen in the future and then take action before it happens (Frese \& Fay, 2001). So, proactive behavior is future-focused and mindful which emphasizes spontaneity, change orientation and future orientation. Some scholars regard it as the process of socialization driven by individual themselves.

At present, the definition of integration of the connotation and type of proactive behavior is inconsistent. An integrated concept of proactive behavior based on individual behavior pattern. They believed that individual proactive behavior combines the following 3 types of behaviors: 1) Aimed at changing the internal environment of the organization, including individual innovation, problem prevention, control behavior; 2) Aimed at changing employee themselves or making themselves more fit to the organization. Including feedback observation, feedback seeking, career initiative, etc.; 3) Aimed at changing organization's strategy or alignment with the external environment. Including strategic scanning, issue selling credibility, etc. (Parker \& Collins, 2010). Proactive behavior is a dynamic process, including anticipation, planning and action directed toward future impact. And divide it into five dimensions: 1) Form, contains feedback-seeking and social network-building; 2) Intended target of impact, there are mainly three aspects of influence, the influence on oneself, on others and on the organization; 3) Frequency, which is more about the frequency of what happens; 4) Timing, the extent to which an action takes place in a particular situation, stage, or moment; 5) Tactics; there are different strategies for different behaviors. For example, feedback-seeking will utility both inquiry and monitor strategies (Grant \& Ashford, 2008). From the perspective of performance output, the performance of employees' job roles divided into three types: Adaptivity, Proficiency and Proactivity. Proactive behavior is individual spontaneity to make changes to the working system or work role or itself (Griffin et al., 2007).

The first characteristic of proactive behavior is acting in advance, in which employees think, plan and act on the future results before the event, select, modify and even create the desired results. The second characteristic of proactive behavior is the intended impact. When an employee chooses proactive behavior, he or she chooses to change the environment purposefully. In general, proactive behavior emphasizes the spontaneity, change orientation and focus on the future of individual behavior.

\section{Antecedent Variables}

The antecedent variables of proactive behavior can be roughly divided into indi- 
vidual and organizational factors. Individuals such as individual characteristics, individual motivation, ability knowledge, etc. Organizational factors include accountability, ambiguity, autonomy, leadership, organizational context, etc.

Individual factors The individual's own factor is an important factor affecting the employee's proactive behavior, including 3 aspects: individual trait, individual motivation, knowledge and ability. Proactive behavior is closely related to individual characteristics. Existing researches have found that individual characteristics mainly include proactive personality, sense of responsibility, neuroticism, goal orientation and other factors that affect proactive behavior. Proactive personality, individual initiative and taking the initiative to assume responsibility all have strong predictive effects on proactive behaviors (Crant, 2000). As the theory of work motivation is one of the theoretical bases for the study of proactive behavior, a large number of scholars have studied the impact of work motivation on proactive behavior. Individual role width self-efficacy and flexible role positioning have positive effects on taking responsibility (Fay \& Frese, 2006). Job search self-efficacy can also affect individual's proactive behavior. High levels of knowledge, skills, and abilities are often associated with higher levels of personal motivation. If employees want to show more proactive behavior, they need to have knowledge, skills and corresponding abilities related to the job (Brown et al., 2006).

Organizational factors Among organizational factors, more and more researches focus on the influence and mechanism of different leadership styles on employees' proactive behaviors. The support of leaders has a positive effect on the generation of employees' proactive behavior. Leadership support can foster a higher degree of autonomy among employees and enhance their ability and willingness to initiate future-oriented changes. Safety based support from leaders (In the form of leader availability, encouragement, and non-intervention) positively predicts positive work behavior by increasing employee role breadth, self-efficacy, and autonomous motivation. In particular, individuals high in attachment anxiety rely more on leader secure-base support to foster their role breadth self-efficacy, then improve their proactive behavior. Transformational leaders care about their subordinates and encourage individuals to think in new ways and exceed expectations (Williams, Parker, \& Turner, 2010). Through the establishment of the atmosphere of mutual trust, let them become innovative and more open, which has a positive incentive effect on the individual initiative. But existing research also suggests that while leadership support, such as encouraging ideas, may increase employees' motivation to engage in proactive behavior, it does not always have a positive effect. Passivity and dependency may be fostered by the implementation of employee recommendations (Parker et al., 2006). Job characteristics are thought to influence individual motivation and behavior in an organization. Appropriate job design can promote the individual's sense of control and efficiency, and can improve the employees' proactive behavior. On this basis, job autonomy, job complexity, task integrity, sense of 
control and work pressure and so on become the factors that affect employees' proactive behavior. In general, the existing literature focuses more on the positive performance outcomes of proactive behaviors. Personal work motivation is mainly characterized by stress and stress (high control motivation), no intrinsic interest in work compensation or identification (low autonomy motivation), and proactive behavior can deplete employees' resources and lead to work stress. In other words, when employees feel pressure and obligation at work, but do not have any compensatory autonomous motivation, proactive behaviors will generate work pressure (Strauss et al., 2017).

\section{Three Ways to Improve Proactive Behavior}

Existing research shows that proactive behavior plays an important role in predicting individual and organizational performance. Therefore, it is necessary to discuss how to improve it. What is discussed here is the employees who are already in the company, so there is no discussion on the improvement approaches at the individual level. What is mainly discussed here is how to improve the willingness and frequency of proactive behaviors at the organizational level such as leadership, job characteristics, organization situation.

1) Leadership Leaders directly change employees' behavior by influencing their motivation. For example, support from the leader for the behavior of employees; emphasizing the value of subordinates and letting them participate in the decision-making process has a significant effect on the occurrence of proactive behavior.

2) Job characteristics Through job design: job autonomy, job complexity and sense of control become the work characteristics that provide employees' initiative behavior; Moreover, job enrichment can promote individual initiative by improving individual self-efficacy and flexible role orientation.

3) Organization situation When the organization has a high atmosphere of procedural fairness, it is easier for employees to take the initiative to assume responsibility. Three organizational situations that affect the occurrence of individual active behavior: accountability, ambiguity and autonomy (Grant \& Ashford, 2008). In addition, the creation of a relatively free environment in an organization leads to employees' initiative.

\section{Conclusion}

As an important factor affecting the effectiveness of individuals and organizations, proactive behavior is of great significance to its research. Based on the review of the existing literature, we can find that the research on employee initiative behavior has achieved fruitful results. However, this paper believes that the theoretical research on proactive behavior should be strengthened from the following aspects:

1) Conduct systematic and integrated research. As proactive behaviors are phenomenon-driven behaviors, the research on them is too scattered and there 
is no concise integration to form a unified research framework.

2) Research on team and organizational Most of the existing researches focus on individual employees. However, in an organization, the power of only one person is limited. In the future, more consideration can be given to the more prominent impact of team and organizational level on organizational performance.

\section{Conflicts of Interest}

The author declares no conflicts of interest regarding the publication of this paper.

\section{References}

Ashforth, B. E., Sluss, D. M., \& Saks, A. M. (2007). Socialization Tactics, Proactive Behavior, and Newcomer Learning: Integrating Socialization Models. Journal of Vocational Behavior, 70, 447-462. https://doi.org/10.1016/j.jvb.2007.02.001

Brown, D. J., Cober, R. T., Kane, K., Levy, P. E., \& Shalhoop, J. (2006). Proactive Personality and the Successful Job Search: A Field Investigation with College Graduates. Journal of Applied Psychology, 91, 717-726. https://doi.org/10.1037/0021-9010.91.3.717

Crant, J. M. (2000). Proactive Behavior in Organizations. Journal of Management, 26, 435-462. https://doi.org/10.1177/014920630002600304

Fay, D., \& Frese, M. (2006). Conservatives' Approach to Work: Less Prepared for Future Work Demands? Journal of Applied Social Psychology, 30, 171-195. https://doi.org/10.1111/j.1559-1816.2000.tb02310.x

Frese, M., \& Fay, D. (2001). Personal Initiative: An Active Performance Concept for Work in the 21st Century. Research in Organizational Behavior, 23, 133-187. https://doi.org/10.1016/S0191-3085(01)23005-6

Grant, A. M., \& Ashford, S. J. (2008). The Dynamics of Proactivity at Work. Research in Organizational Behavior, 28, 3-34. https://doi.org/10.1016/j.riob.2008.04.002

Griffin, M. A., Neal, A., \& Parker, S. K. (2007). A New Model of Work Role Performance: Positive Behavior in Uncertain and Interdependent Contexts. The Academy of Management Journal, 50, 327-347. https://doi.org/10.5465/amj.2007.24634438

Parker, S. K., \& Collins, C. G. (2010). Taking Stock: Integrating and Differentiating Multiple Proactive Behaviors. Journal of Management, 36, 633-662. https://doi.org/10.1177/0149206308321554

Parker, S. K., Williams, H. M., \& Turner, N. (2006). Modeling the Antecedents of Proactive Behavior at Work. Journal of Applied Psychology, 91, 636-652. https://doi.org/10.1037/0021-9010.91.3.636

Strauss, K., Parker, S. K., \& O’Shea, D. (2017). When Does Proactivity Have a Cost? Motivation at Work Moderates the Effects of Proactive Work Behavior on Employee Job Strain. Journal of Vocational Behavior, 100, 15-26.

https://doi.org/10.1016/j.jvb.2017.02.001

Williams, H. M., Parker, S. K., \& Turner, N. A. (2010). Proactively Performing Teams: The Role of Work Design, Transformational Leadership, and Team Composition, Journal of Occupational and Organizational Psychology, 83, 301-324.

https://doi.org/10.1348/096317910X502494 